\title{
BREVE ANÁliSE DOS REFLEXOS DA SEGUNDA GUERRA MUNDIAL NAS OBRAS LITERÁRIAS JAPONESAS
}

Mônica Setuyo Okamoto

RESUMO: Este artigo discute as relações entre literatura japonesa e Segunda Guerra Mundial, a partir das obras de três escritores conceituados: Dazai Osamu, Kawabata Yasunari e Oe Kenzaburo. O enfoque no tema bélico, presente nas três produções, direta ou indiretamente, revela como cada um deles tratou dos impactos psicológicos causados pela guerra e os seus reflexos em suas obras. Palavras-chave: guerra, literatura, Japão, história, consciência.

ABSTRACT: this article discusses the relation between Japanese Literature and Second War, from three writer's works: Dazai Osamu, Kawabata Yasunari and Oe Kenzaburo. The focus on the war theme, in the three works, direct or indirectly, shows how each one treat of psychologies impacts caused by war and their reflexes in their books.

Key words: war, literature, Japan, history, conscience.

\section{Introdução}

Sem sombra de dúvida, a Segunda Guerra Mundial foi um marco na história de nossa civilização. As mudanças decorrentes de uma nova consciência social trouxeram muitos reflexos nos campos acadêmico e político. Na literatura, por exemplo, houveram reações distintas, no que diz respeito às manifestações de pensamento dos escritores. Cada literato, ao seu modo, expressou a sua experiência bélica, juntamente com a sua dor, a sua indignação, o seu temor e, em alguns casos, a sua esperança. O negativismo e a descrença foram provavelmente temas recorrentes, especialmente nas obras produzidas por autores de países derrotados. Entretanto, enquanto uns escolhiam o caminho da depressão, do terror e da barbárie como fontes

1. E-mail setuyo@uol.com.br 
de inspiração de suas obras literárias; outros procuraram no escapismo um feixe de luz no qual pudessem ser conduzidos ou até mesmo transcendidos para um mundo particular, sem conexões com a realidade dura, um sonho, algo próximo de uma experiência surreal.

Neste artigo, pretende-se fazer uma rápida reflexão e análise acerca da Segunda Guerra Mundial na literatura japonesa. Sem a pretensão de um estudo exaustivo, foram selecionadas algumas obras por serem consideradas relevantes ao tema e, principalmente, pelo caráter antagônico entre elas. A primeira obra é Shayô (1947) do polêmico escritor Dazai Osamu que transpôs em boa parte de seus trabalhos sua personalidade complexa. Shayô (Pôr-do-Sol) é uma alusão à própria família do autor que, como muitas outras velhas famílias aristocráticas japonesas da época, entram em decadência, perdendo o seu brilho e a sua força social e econômica com o fim da guerra. A obra seguinte a ser analisada é Yukiguni (1947) de Kawabata Yasunari que procurou outros caminhos para lidar com o período bélico. Ele buscou no ideal inalcançável e no prazer estético a energia vital para enfrentar um mundo em colapso e um Japão que estava perdendo a sua tradição. E por último, analisaremos o conto Animal de Cria (1957) de Oe Kenzaburo que fala sobre os danos psicológicos causados pela guerra numa criança. É bom lembrar que Oe ainda era um menino em 1939 e a passagem para a adolescência do escritor ocorreu durante os conflitos mundiais. Dentre os três escritores Oe Kenzaburo fora o mais engajado nas questões políticas e sociais, ao contrário do idealismo de Kawabata e da autodestruição de Dazai.

A guerra como tema literário tem sido uma terra fértil e bastante trabalhada em todos os tempos da História. Entretanto, notamos que ela pode produzir efeitos completamente paradoxais dependendo das bases pessoais do próprio artista. Assim sendo, por meio das obras destes três grandes escritores espera-se esboçar os reflexos, por vezes completamente distintos, da Segunda Guerra Mundial na literatura japonesa

\section{A Literatura Japonesa Pós-Guerra}

Após o famigerado pronunciamento do imperador japonês em cadeia nacional de rádio da rendição incondicional do Japão em agosto de 1945, iniciou-se dias depois a ocupação americana. O objetivo das forças de ocupação era democratizar e desmilitarizar o Japão. Eles queriam derrubar qualquer vestígio da antiga estrutura política e social nipônica que fora a promotora do imperialismo japonês na Ásia. Obviamente, com isso, criou-se um clima de medo e insegurança na população japonesa que se encontrava desnorteada quanto ao futuro de sua nação.

No campo literário, os reflexos do período conturbado de conflitos internacionais tiveram início antes mesmo de estourar a guerra do Pacífico. Na década de 1930, o governo japonês implantou leis rígidas de censura nos meios de comunicação em geral chegando, inclusive, a "incentivar" os literatos a promoverem a guerra, em favor do Estado. Era comum os escritores japoneses serem enviados 
para os campos de batalha como repórteres para cobrirem os assuntos de guerra. Todo esse "incentivo" trouxera como resultado propagandas bélicas glorificando as ações dos dirigentes. Um outro recurso foi resgatar o passado histórico das tradições feudais japonesas como meio de intervenção na opinião pública. As sagas de samurais legendários foram os preferidos, normalmente publicados em séries nos jornais de grande circulação. Alguns resistentes ao regime de censura do governo, como Kobayashi Takiji, foram presos, torturados e mortos. Outro empecilho para a criação artística japonesa foi o racionamento de papel em 1941. No entanto, depois de agosto de 1945, a vida literária japonesa seguiu um novo rumo. A maior parte das revistas literárias mais importantes da época tiveram que encerrar as suas atividades. Novas revistas foram fundadas ou restabelecidas tendo como base: a reconstrução, o período de humanismo e as reflexões sobre as conseqüências da guerra do Pacífico para a nação japonesa. Esses temas foram os carros-chefes que conduziram os artistas a produzirem não somente livros sobre o assunto, mas a consciência social da geração pós-guerra.

\section{Shayô - a decadência da aristocracia japonesa}

O romance Shayô é o resultado de uma complexa alquimia realizada pelo seu autor. Dazai mistura dois pólos opostos: o lado rebelde que se posiciona contra as convenções sociais e em favor da luta pela sua derrocada representada pela protagonista Kazuko; e o lado niilista, na figura de Naoji, que tem um comportamento desordeiro, uma vida errante. Sua enorme descrença o imobiliza a tomar qualquer iniciativa para acabar com sua insatisfação. Segundo os críticos literários japoneses, essas duas personagens são transmutações da psique de Dazai.

De fato, a obra lembra muito a situação da aristocrática família de Dazai, porém boa parte do romance fora inspirado no diário de Ôta Shizuko, sua amante e mãe de seu filho. Essa passagem da vida do escritor é muito semelhante à vida da personagem Kazuko que decide ter um filho de um escritor que ela admirava, contrariando as regras de moralidade da alta sociedade nipônica da época.

Durante o período de guerra, a jovem Kazuko muda-se para o interior do Japão juntamente com sua mãe. Além dos problemas de saúde da matriarca, Kazuko tem de enfrentar: os problemas financeiros da família, que já fora poderosa no passado, e o seu irmão Naoji que volta da guerra transtornado. Destaque especial é dado pelo autor à mãe, personificação do status de uma geração bem-nascida. Toda opulência de tempos atrás fora devastada pela guerra, restando apenas as lembranças tristes de velhos hábitos e tradições.

Para Dazai, somente nos momentos de grande crise é que conhecemos a verdade. A guerra foi, de certa forma, $o$ estopim para as mudanças de comportamento social, e para a transgressão ao código de moral e conduta criados pela sociedade, casos de Naoji e Kazuko. A metáfora do pôr-do-sol (shayô) representa também o fim de uma classe, de uma era, de uma tradição. 


\section{Yukiguni - Kawabata Yasunari}

Kawabata Yasunari laureado com o Prêmio Nobel de Literatura foi também conhecido por sua visão muito peculiar de consciência estética. Produziu vários artigos sobre crítica literária, nos quais discute a questão da natureza da literatura e sua função estética. Suas teorias são notadamente de influência ocidental, no entanto, suas obras resgatam e ressaltam os valores mais tradicionais da cultura japonesa. Podemos observar nas obras de Kawabata uma linha teórica voltada para o plano estético, ou seja, a beleza da literatura na visão desse escritor está na linguagem, na forma, nos recursos retóricos. A palavra e seu alto poder sugestivo, simbólico e associativo. Ele busca recursos psíquicos como o sonho, por exemplo, na apreensão dos momentos breves de lirismo, uma espécie de apelo ao subconsciente. Do outro lado da moeda, Kawabata explora temas ligados ao antigo Japão feudal, ou seja, surge a sua consciência nacional. Busca na música, no folclore regional e outras manifestações dessa nacionalidade a ligação de seu mundo presente com o passado que estava sendo extinguida com os conflitos internacionais.

Yukiguni (1947) é considerada a sua obra-prima e um exemplo dessa dualidade: o estético e o ideológico. A história se passa no Japão nos idos de 1930 e conta um fato banal de um rico citadino de Tóquio, Shimamura, realizando uma viagem de trem para uma pequena cidade ao norte do Japão, quando de repente ele se depara com o reflexo de uma moça na janela do trem, Yoko, que estava sentada do outro lado. Como um passageiro de uma viagem longa que fica entediado olhando para a monotonia da paisagem, Shimamura tem essa monotonia quebrada pelos olhos brilhantes de Yoko refletidos na janela do trem. Aquele instante tão curto, mas extremamente belo, torna-se o âmago da obra.

Shimamura cria uma obsessão por aquela beleza idealizada, intocável. A abertura da cena de Yukiguni revela bem a visão estética de Kawabata de beleza inalcançável, pura, sincera, imaculada. A vida, ainda na concepção deste escritor, é uma miscelânea de fantasia e realidade, coisas puras e não puras, belas e feias. O literato tinha, portanto, a função de escolher e reorganizar alguns aspectos da vida que fossem belos e puros para produzir uma realidade que estivesse acima do cotidiano e da vida mundana de um cidadão comum. A personagem Yoko é a escolhida por Kawabata para representar essa beleza pura. Os heróis de Kawabata só almejam aquilo que é inatingível e que parece distante. A beleza da vida está justamente não na concretização de um desejo, mas no esforço para se alcançá-lo. Viver por um ideal, contanto que ele seja puro e bonito, é mais uma faceta de sua visão literária.

Essa obra levou dez anos para ser finalizada e fora produzida durante o periodo da Segunda Guerra Mundial, portanto sob o impacto de um conflito internacional. Ao contrário de Dazai que fala da decadência das famílias tradicionais japonesas, Kawabata faz uma "viagem ao passado " para uma cidade do interior onde eram mantidas essas tradições passadas. Ele não só resgata uma atmosfera do passado, 
com a figura da gueixa e do ryôkan ${ }^{2}$, como também recupera canções regionais e outros elementos da cultura nipônica, dando um teor de importância e chamando a atenção para o perigo da extinção dessas tradições que eram passadas de geração para geração. Certamente a guerra abalou as estruturas sólidas dos japoneses quanto ao seu maior patrimônio histórico: a sua tradição, representada pela figura do Imperador, das gueixas, das antigas hospedarias, das canções regionais. Kawabata não buscou nessa viagem ao passado um refúgio dos problemas sociais e políticos do mundo contemporâneo, pelo contrário, ele fez uma reflexão sobre a morte e a "função" da literatura. Nada mais natural que falar da morte em tempos de guerra.

Para o autor de Yukiguni, a pessoa só terá uma vida plena se estiver preparado para morrer a qualquer hora. A morte é um elemento constante na vida dos heróis e heroínas de Kawabata, pois é o preço de uma vida intensa. O ser humano revela um olhar diferente para a natureza quando tem consciência de que pode morrer ainda jovem, ele se torna o sujeito mais qualificado para ser um sonhador. Considerando o conjunto desses conceitos, digamos que Yukiguni passa a idéia de que uma vida longa não significa, necessariamente, uma vida plena, veremos que para Kawabata só a presença eminente da morte, da separação brusca ou da idealização de algo é que farão o indivíduo ter essa sensação de plenitude e intensidade e, que os escritores, espiritualmente mais sensiveis, seriam os responsáveis em apresentar esse momento "belo"

\section{Animal de cria - a transformação psicológica}

É comum que em situações de penúria e tensão, como é o caso da guerra, ocorra um retrocesso da evolução humana, ou seja, o indivíduo não consiga mais distinguir quem são seus inimigos naturais. Conseqüentemente, a morte humana é banalizada pelos envolvidos no processo. No entanto, a guerra na visão das crianças pode ter significados completamente opostos. Pode ser considerada uma tragédia, caso seja vítima direta do conflito; ou então se suas almas forem ainda muito puras, a guerra pode ter uma conotação lúdica.

Habitantes de um pequeno vilarejo do interior do Japão viviam isolados dos acontecimentos mundiais e do resto do Japão, durante a Grande Guerra. Segregados pelos habitantes da cidade, essas pessoas eram vistas como animais sujos. Os transtornos causados pelo conflito não atingiam diretamente as crianças desse vilarejo, pelo contrário, os aborrecimentos dos adultos (os sistema de correio havia sido suspenso, bem como o crematório, a escola e outros serviços essenciais) eram para elas motivos de brincadeira. Crematório improvisado, notificações de morte, nada disso penetrava no universo particular das crianças desse vilarejo. Elas passavam o dia caçando cães selvagens, tomando banho no rio, brincando com outras crianças.Até o dia em que um avião americano cai nas redondezas e mobiliza

2. Hospedaria em estilo japonês. 
os habitantes da aldeia que vão à caça dos inimigos. Um soldado negro americano é capturado, seu destino fica suspenso, enquanto os habitantes do vilarejo e as autoridades da cidade discutem, burocraticamente, o que fazer com o prisioneiro. Durante esse período de indecisão, nasce um sentimento puro de afeto entre o soldado e o menino que fica encarregado de alimentá-lo. Essa afeição parece ser mútua, inicialmente, e acaba contagiando as outras crianças do vilarejo. Todas se aproximam e se divertem com o novo "animalzinho de cria", um cão selvagem. Entretanto, quando a cidade decide executar o soldado, a vida do menino sofre uma dura transformação. Primeiro com relação à decisão dos adultos da cidade que causa uma ruptura no sentimento que havia nascido do contágio social entre o menino e o soldado; depois a reação do soldado americano que para proteger sua vida, coloca em risco a do menino, revelando uma faceta de traição de um afeto unilateral. Os danos dessa situação serão irreparáveis para essa criança que perde a sua pureza infantil prematuramente por culpa dos adultos que o decepcionam. Obviamente, num período bélico, o mundo psicológico é regido por outros fatores que refletem na maioria de nossos instintos. A sociedade perde a noção do individual e nasce um sentimento coletivo de psicose movido, em geral, pelo fanatismo, pela cólera ou patriotismo. A morte de um indivíduo, que tem importância apenas para as pessoas próximas, não tem mais importância para o agregado humano. Quando o secretário é morto ao lado do menino, este se torna indiferente ao fato, sinal de que ele já fazia parte do coletivo adulto, desse agregado humano.

Os meninos, por sua natureza combativa, costumam brincar com elementos de agressão, ou seja, a guerra pode ser um jogo, uma brincadeira, o que revela a existência inata nas crianças de um instinto de luta, no conto, os meninos do vilarejo: caçavam cães selvagens, tinham inimigos declarados (os meninos da cidade), batiam em outros meninos puramente como demonstração de força e domínio, não se importavam em brincar com os ossos dos defuntos do crematório. Por razões de defesa, os meninos costumam usar seu corpo como instrumento de luta, a arma mais primitiva do ser humano. Segundo os psicólogos, até a préadolescência o menor é extraordinariamente combativo, somente na fase posterior, a sociedade tenta moldar em virtude de idéias morais impostas pelo meio social. No caso do menino do vilarejo, a guerra tinha uma conotação lúdica, fazendo parte de seu mundo individual, até o momento em que a conotação de guerra do mundo adulto destrói essa pureza.

\section{Conclusão}

Para avaliarmos quais foram os reflexos da Grande Guerra nas obras literárias desses três autores precisamos levar em consideração alguns aspectos peculiares de cada um deles. Tanto Kawabata, quanto Dazai já eram adultos no período dos conflitos, ao passo que Oe era ainda um menino. Estamos falando de duas gerações 
distintas que viveram o período de transição do Japão. As diferenças continuam também no plano literário, especialmente entre os dois contemporâneos. Kawabata era contra os princípios de vida de Dazai, cobertos de nuvens escuras na opinião dele. Para o autor de Yukiguni o estilo de vida de Dazai era desregrado, portanto totalmente vazio e sem qualidades vitais, espiritualmente estéril e não produtivo. Dazai fora um rebelde por princípio e muitas vezes contraditório, ao mesmo tempo que ele defendia o progresso e a democracia do Japão, ele sofria com a perda de alguns valores tradicionais japoneses. Sofrimento compartilhado de certa forma por Kawabata que também busca inspiração no Japão antigo, em seu regionalismo e velhos costumes.

O tema da guerra revelou-se em Oe na forma de militância em sua juventude. Ele lutou por uma literatura engajada de conteúdo forte, esquerdista e desconcertante. Já em Dazai, fica difícil concluir uma posição. Ele mesmo teve dificuldades de encontrar respostas às suas questões, procurou a plenitude e buscou algo que não sabia.

Podemos arriscar e dizer que as conseqüências da guerra na população japonesa foram profundas, mas escritores, em geral mais sensíveis, como Dazai, Kawabata e Oe foram atingidos espiritualmente em proporções maiores e viveram uma grande pressão psicológica. Dentre os três, Dazai talvez tenha vivido a neurose da guerra mais intensamente: a tensão entre os impulsos orgânicos irracionais e os códigos de conduta eram constantes em seu interior. A conseqüência imediata disso tudo fora a frustração e o surgimento de uma agressividade e descontentamento contra os líderes políticos. Outras vezes essa impulsão fora canalizada para o sexo ( Dazai teve uma vida sentimental instável) ou para a religiosidade (o autor de Shayô abraçou o Cristianismo).

Enfim, apesar das diferenças de estilo de vida, idade e visões literárias, esses três escritores japoneses tiveram em comum a experiência da guerra e a preocupação com a perpetuação das tradições do passado. Temeram pelo seu completo extermínio. Suas obras certamente alteraram a consciência coletiva da guerra por parte dos japoneses, por várias décadas.

\section{Bibliografia}

BRYAN, Ingram. The Literature of Japan. London: The Home University Library, s.d.

DAZAI, Osamu. Pôr-do-Sol. São Paulo: Gráfica Editora Hamburg Ltda, 1974. Tradução de Antonio Nojiri. P. 108.

KAWABATA, Yasunari. O País das Neves. Tradução: Neide Hissae Nagae. São Paulo: Estação Liberdade, 2004. p. 160.

OE, Kenzaburo. 'Animal de Cria'.Tradução de Tae Suzuki. In: WAKISAKA, Geny. (org.).Contos de Oe Kenzaburo. São Paulo: Centro de Estudos Japoneses da USP, 1995. P.104-120. 
ÔUCHI, Chikara. Nihon no Rekishi. Fashisumu heno michi. 24. Tóquio: Chûkobunko, 1975. p. 487.

UEDA, Makoto. Modern Japanese Writers and the Nature of Literature. California: Stanford University Press, 1976. p.145-219 